\title{
MITTEILUNGEN UND NACHRICHTEN
}

\section{Forst- und Holztagung 1977}

In der Zeit vom 10. bis 13. Mai 1977 finder in Hamburg 80, Leuschnerstraßse 91, die Hamburg-Reinbeker Forst- und Holztagung 1977 statt. Es ist folgendes Programm vorgesehen:

Montag, 9. Mai 1977

Sitzung des Präsidiums der Deutschen Gesellschaft für Holzforschung e. V.

Dienstag, 10. Mai 1977

Forst- und holzwirtschaftliches Symposium.

Die Bundesforschungsanstalt für Forst- und Holzwirsschaft im Dienst der Holzversorgung und Holzverwendung

Empfang des Bundesministers für Ernährung, Landwirsschaft und Forsten

Mittwoch, 11. Mai 1977

Forst- und holzwirtschaftliches Symposium (Fortsetzung)

und

Gespräch der Deutschen Gesellschaft für Holzforschung e. V. über die mechanische Holzsortierung (stress grading)

Gesellschattsabend

Donnerstag, 12. Mai 1977

Internationale Informationstagung

Tropenhölzer für unsere Holzversorgung - heute und morgen und

Vortragsveranstaltung anläßlich des 50jährigen Bestehens des Instituts für Arbeitswissenschaft (Iffa)

Donnerstag, 12. Mai, und Freitag, 13. Mai 1977

Sitzung der IUFRO-Arbeitsgruppe $\mathrm{S} 4.06 .02$

Staatliche und private Investitionspolitik zur Entwicklung der Holzindustrie

Donnerstag, 12. Mai, bis Dienstag, 17. Mai 1977

Gemeinsame Sitzung des UNESCO-Projektes "Man and the Biosphere“ und der IUFRO-Arbeitsyruppe $\mathrm{S} 1.01 .05$

Interdisziplinäre Erforschung der Okosysteme tropischer Regenwälder

\section{Friedrich Meiss $\dagger$}

Am 1. Februar 1977 ist Forstdirektor i. R. FRIEDRICH MeIss im Alter von 93 Jahren in Uberlingen/Bodensee gestorben. Forstdirektor Meiss hat über 40 Jahre lang das Markgräflich Badische Forstamt Salem geleitet und hier eine Waldbauleistung erbracht, die unter dem Begriff der "Salemer Waldwirtschaft" weit über die örtlichen Grenzen hinaus bekannt wurde und vielfach Anerkennung und Würdigung erfahzen hat.

Bei allem Wandel, dem auch die Waldwirtschaft unterworfen ist: Meiss hat in Salem Maßstäbe gesetzt und damit Bleibendes geschaffen. 